\title{
Deconstruction of Mandala's Puri Agung Karangasem
}

\author{
Agus Kurniawan ${ }^{1}$, P Rumawan Salain ${ }^{2}$, N K Acwin Dwijendra ${ }^{3}$ and I G N Anom Rajendra ${ }^{4}$ \\ ${ }^{1}$ Doctoral Study Program of Engineering Science, Faculty of Engineering, Udayana University \\ ${ }^{1,2,3,4}$ Study Program of Architecture, Faculty of Engineering, Udayana University \\ *Email: agus_kurniawanst@yahoo.com
}

\begin{abstract}
ABSTRAK
Abstract-Deconstruction is a method, a thought as well as a theory created by Jacques Derrida, a philosopher and critic of French literature. Derrida himself was reluctant to determine exactly what deconstruction is. Derrida only mentions what is not, not what is yes. However, the thought that is currently on the decline is actually attracting the attention of architects so that his fame is revived. If you follow Derrida's way of thinking surely no one will be able to explain what deconstruction is, because once he explains that the deconstruction revealed is not deconstruction. To better recognize and understand the strategy of deconstruction in architecture, the way Bennedikt should be imitated, as a method of analyzing architectural works using the perspective of deconstruction. In this paper we will try to read an architectural work, using Bennedikt's method. The work that will be the object of reading is Puri Agung Karangasem. The main objective to be obtained through this paper is to find out whether the work can be classified into deconstruction architecture, to deepen the understanding of deconstruction itself and at the same time train sensitivity in thoroughly reviewing an architectural work through an observation angle.
\end{abstract}

Keywords: Mandala Deconstruction, Puri Agung Karangasem

\section{INTRODUCTION}

In talking about theories and methods in architecture, many opinions arise from philosophers, to be able to popularize methods or theories that were sparked through his followers or the next generation. Where this is proven by the emergence of "Deconstruction", which is one of the contemporary/contemporary architectural movements or kiwari, this idea emerged at the end of the 20th century which was very controversial, because this was a rebellion against the capabilities of modern architecture. Deconstruction thinking is as an attitude to free yourself from the shackles of old architectural thinking, the legacy of modern architecture which is considered not to represent the existing reality. It is understandable that these rebellious attitudes cause a lot of boisterous responses, whether they like it or not, from the architects and the general public. The way of thinking and delivery in expressing something is difficult for many to understand, so it takes time to be understood by the public.[4][5][16].

Deconstruction cannot be defined, his thinking seems at first glance complicated by the usual architectural disclosure of the realm of modern architecture in particular and architecture in general. From this statement, many argue that the Deconstruction movement is meaningless, making it up and will fade with a relatively short time. Deconstruction as the latest architectural movement may be too early or difficult to now be used to assess problems, the superiority of Deconstruction architecture in terms of his thinking and ability to design architecture. Why did such a thing become so? In the ideas and concepts of architectural design Deconstruction is based on philosophy, strategies and methods of reading and reading them carefully in literary discourse that was sparked by a literary thinker and critic, namely a philosophy of Jacques Derrida.

To understand and know more fully about deconstruction architecture, the easiest way to do this is to read an architectural work using the Deconstruction approach, as did Michael Bennedikt on "The Kimbell art Museum" by Louis I Khan. In the discussion later, to be able to recognize and understand the Deconstruction Method in architecture using the Deconstruction perspective. By paying attention to the background above from the uniqueness in the all-controversial Deconstruction architecture, the author uses Puri Agung Karangasem as Puri Agung Karangasem in this discussion.[50][16].

\section{LITERATURE REVIEW}

Given the broad scope of the Deconstruction theory that encompasses discipline, the discussion will be focused from the perspective of a review that refers to the method of Michael Benedikt in an essay: "Deconstrukting The Kimbell, an Essay on Meaning and Architecture". The method includes an understanding of 4 aspects, namely:[4][5]

A. Differance:

Differance according to Derrida is not a concept or a word, while according to Culler it can literally be defined into three things as follows:

1) The system of universal differences, spatial / distance / spatial settings, and differences between things / two things; the attention given is not to a vocabulary itself, but to the dimension where as long as the dimension of something / two-thing in a vocabulary separates itself from one another and arises. 
2) Deferral process (delay, suspension of obedience), crossing, surrender, delay, suspension, release, protraction, etc .; a spacing in time.

3) Different notions, notions of disagreement, disagreement, or even concealment.

B. Hierarchy Reversal:

The previous discussion of the existence and absence of classifying into a reversal of the hierarchy, when moving from binary operations into double difference schemes. The definition of hierarchy according to Thoreau in Walden, which compiles a theme of contradictory metaphors which are metaphysical statements about nature and culture, concerning limited and unlimited things, literal and figurative. In Western metaphysics the idealism of 'existence' according to Derrida has caused all systems of difference and categories to be hierarchical. Hierarchical in the sense that one term dominates by turning/ignoring other terms in the presence of the extras. Derrida further pointed out that difference is the source of all categories and opposition, and if the terms after they have been arranged in a certain philosophy they are rarely treated the same. These terms are subordinated and hidden/suppressed, although it is logically necessary and preconditional for the whole scheme.[4][5][16].

In life everything in this world is a binary opposition. These pairs apply in all fields, in language for example there is 'parent sentence' there is 'clause', in scientific thinking patterns always consist of 'primary premise' and 'secondary premise'. Likewise in the field of architecture there are pairs between the location of the building and the position of the building, exterior and interior, building mass and building plans, building structures and building construction. In the pair the same rule applies, namely the primary directs the secondary and vice versa, the secondary explains the primary. Such relationships are called vertical or hierarchical relationships that are commonly found in modernist architecture. Deconstruction against such order, especially the logical construction and order. In deconstruction architecture there is no primary and secondary in a pair, both are equal. Therefore deconstruction architecture is difficult to be accepted by people who are accustomed to living in tiered situations because it is not logical. But it can be understood that the thinkers of the deconstruction school are totally new and indeed intended for new societies.[4][5][16].

\section{Marginality dan Centrality (Marginalitas \&}

Centralitas).

Marginality and centrality can be used in terms of 'not important' and 'important' in sequence, related to the metaphor of spatiality. The understanding of these two terms is as follows:

1) Maginality / marginality:

Marginality is showing closeness to boundaries, the periphery of the outer boundary, and the border to what is inside and what is outside. The word margin has directionality built into/central collars/central regions. Margin is close to the threshold, but not the boundary itself and has an area, a meeting and covers the inner border of the border itself.

\section{2) Centrality:}

Centrality is showing the idea of the inward and central/heart, where the meaning/meaning is concentrated and "gravity", the points where the action/step originates from within and the destination where the action/step finally arrives from wherever it comes. The centers are also defined according to their embeddedness, their incidence, or their distance from outside in each direction. If outside there is danger, then in the marginal there are preventive measures, and at the center/central is security. [4][5][16].

D. Iterability and Meaning.

To understand Iterability and Meaning is related to Derrida's concept of 'writing'. As for understanding the meaning of writing, it can be done through history as a means to trace it. Because Derrida talks about history in a different way, which is not as a series of meanings, but as traces that can be traced. According to Derrida, if history is a trail, then people who do not witness it cannot speak of anything about it. The trail is essentially 'mute', although it leaves une cicatrice sur la carte (used on the map). Pure imprint is differance. Derrida further added that: "The primordial (original, first) ideas should be based on impressions, and not vice versa. These proto-writing began to work as the origin of meaning. Because it is temporary in nature, meaning does not never appear just like that, but always in a state carried in the 'movement' of the trail, which is meant as "that gives meaning".[4][5][16].

\section{METHODS}

The research approach used in this research is descriptive qualitative research. Qualitative research is conducted on natural objects that develop as they are, are not manipulated by researchers and the presence of researchers does not greatly affect the dynamics of these objects. Descriptive research discusses the deconstruction of the mandala in Puri Agung Karangasem and describes it carefully and measurably. Data collection techniques used in this study were observation techniques, interview techniques, and documentation. This study uses a qualitative research method with an emic approach, researchers assume that human behavior is patterned in the pattern system itself. The aim is to deconstruct and decompose the mandala in Puri Agung Karangasem by deconstruction [6][7].

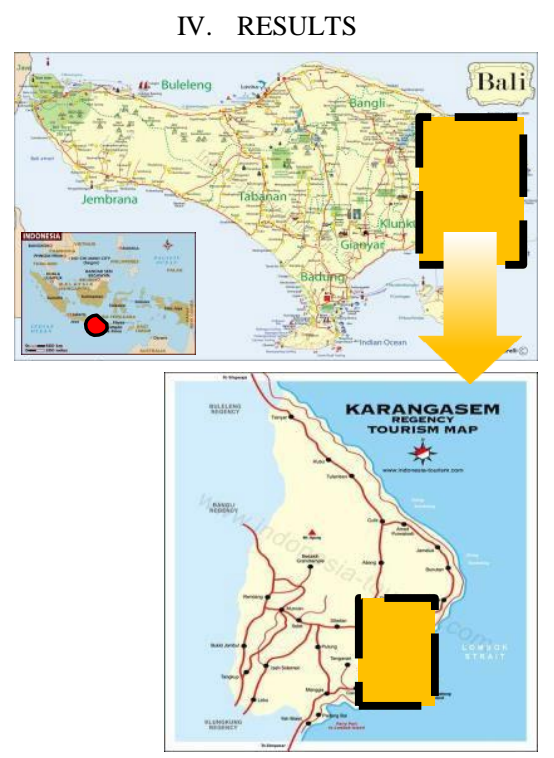


Fig. 1 Research Sites

Puri Agung Karangasem, the layout does not follow the general spatial pattern of puripuri in Bali. But following the spatial pattern of the temple that uses the concept of Tri Mandala, where the spatial layout of the castle is divided into three parts, namely main, intermediate and contemptible. This resulted in the distribution of spatial planning in Puri Agung Karangasem to be simpler compared to other great castles. Based on the results of interviews, this castle began to be built since the 18th

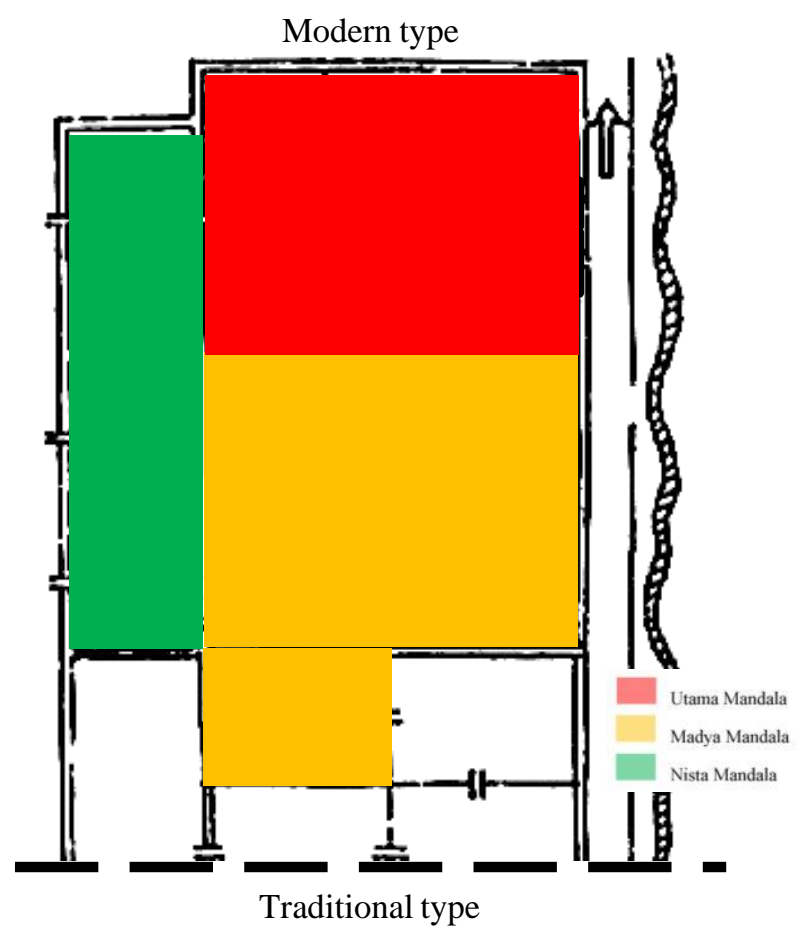

century. [2][3][8][9].

Fig. 2 Mandalas of Puri Agung Karangaem

Puri Agung Karangasem discussed in this study is the modern type. The forms in this castle building nuanced cross-cultural architecture, which is seen in each building due to acculturation of Balinese Traditional Architecture with foreign cultures such as China. The influence of this outside culture is the impact of the involvement of Chinese architect named Lo To Ang in collaboration with local undagi. [10][13] This influence can be seen in architecture, both buildings and decorations, such as carved ornaments on the doors, windows, door decorations there are barong sai ornaments and other ornaments. There is also an entrance from Nista Mandala to Madya Mandala in the form of a towering pagoda with a height of 25 meters using brick material decorated with puppet motifs, which is a creative masterpiece of human genius when the castle was built. [2][3][8][9].

Mandala Puri Agung Karangasem is divided into three sections as described. The first page (Main Mandala), has three spatial planes, namely bancingah, robotic subjects, and sanken. Bancingah is also known as a serving restaurant in this castle. Also there is another uniqueness that is on this page there is a typical Kori Agung Puri Agung Karangasem on the perimeter wall in the west, which forms a three-storey grand kori roof and at each level there are niches filled with Ganesha statues.[14][15]

The second page (Madya Mandala), is a unique page, because in the southern part of this page a Gili building was built or called Bale Kambang. There is a bridge located on the west side of Bale Kambang which connects it to the second courtyard. Another unique building that can be found on this page is the Old Gedong which has an open front which serves as a place to watch the performing arts held at the kale's bale. Old Gedong can also function as a place to carry out various ceremonial activities. [3][8][9][11]

The third page (Utama Mandala) is part of the center of the castle which functions as the residence of the king and his family. The king's residence building was named Gedong Maskerdam, which at the beginning of its construction was called Gedong Amsterdam, a city name in the Netherlands. .[14][15]. Next to the south of Gedong Maskerdam was Bale Pemandesan. On the west side of Gedong Maskerdam, we can find Bale Pawedaan which is a sacred building. Whereas at the back of the Gedong Maskerdam there is the Gedong Londen which is surrounded by other gedongs such as the Betawi Gedong, Yogya Gedong and Ekalanga.

\section{DISCUSSION.}

For the study of the Karangasem Puri Agung case study, so here the writer learns to apply the principles of Deconstruction Architecture with a case study, how can we find the principles of Deconstruction Architecture in this case study building, we start from:

1) Differance

The principle of differance in the Deconstruction architecture when related to Karang Agung Temple Puri, we can try to discuss through reading the blueprints on the Main, Madya and Nista Mandala which is like a sketch of the floor plan. The spatial plan in Puri Agung Karangasem does not follow the puri spatial pattern in general in Bali, but rather follows the temple pattern that uses the Tri Mandala concept. The spatial distribution in Puri Agung Karangasem is simpler compared to other castles in Bali.

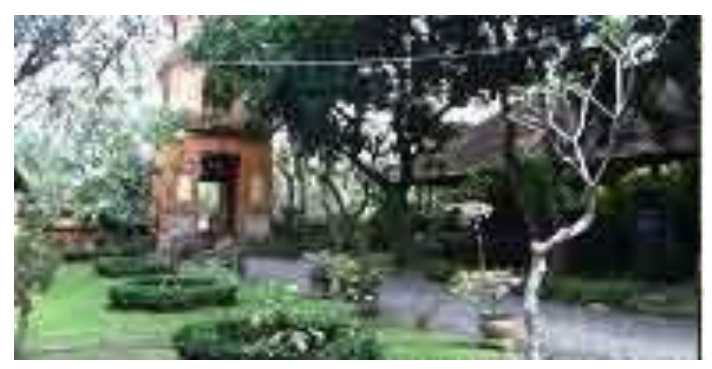

Fig. 3 Nista Mandala

To understand differance must have at least two elements, two members of a sign system, complementary ideas, or not the same sign or ideas that are replaced from themselves into another context. The 'presence' of something cannot be distinguished without the other being 'absence', as it cannot have 'black' without 'white', or 'up' without 'down', cannot have 'left' without 'right' etc. Absence lies behind and always reflects existence. Existence and absence are the most fundamental opposition 
to the most multivarious differance operations. Definitions that describe the secret of differance will in fact only emphasize that, if differance produces differences (as there are between two contradictions), the differences precede meaning, both structural and genetic. So there is no time frame involved in differance, other than proto trail or proto time.

According to Culler in Differance there is a Diferral process which means Delay or spacing, this can be seen in the Site Plan, where at the main entrance to the south of the monument, the architect installs 4 statues (1Pairs of large statues and a pair of small statues located on the side ). The position of this statue is about 50 meters to the main entrance of the building, because the statue is not its entrance, then the distance of 50 meters can be called an area of delay (Spacing) to get to the main building, because the statue is not as a boundary for a building .

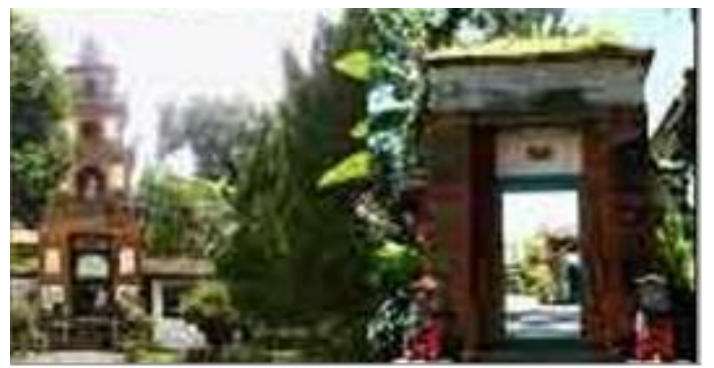

Fig. 4 Nista Mandala section functioned as a place for guests to prepare to enter the deeper castle area

For the term there are two differences such as "absence and presence", this condition can be felt when we enter early after passing through the statue, that we are already inside the site, even though we are still outside the building but already felt inside the building. This happens because the statue's presence is not as an entrance and not as a barrier but as a giver of welcome, seeing such a function as if the statue was "There and Nothing" in terms of function as the main entrance.

2) Hierarchy Reversal

In this Karangasem Puri Agung design, it is very difficult for us to read what is meant from Deconstruction architecture such as the reversal of hiraraki. However, it will try to be able to uncover the 'reversal of the hierarchy' in this architectural work.

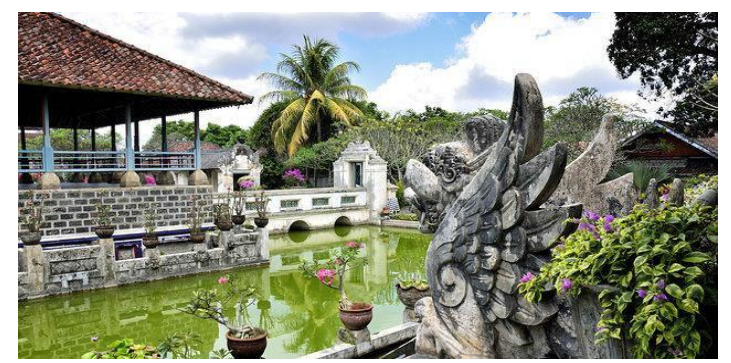

Fig. 5 Decoration and ornament in Madya Mandala

In the Main Mandala all settlements are as usual, while in Madya Mandala and Nista Mandala are completed with an abundance of decoration and ornaments. Thus it is clear that we can settle dominantly on the outside or Madya and Nista Mandala, while for the inside or the Main Mandala is very simple. So according to the author's perspective that this can be said as a "reversal of the hierarchy".

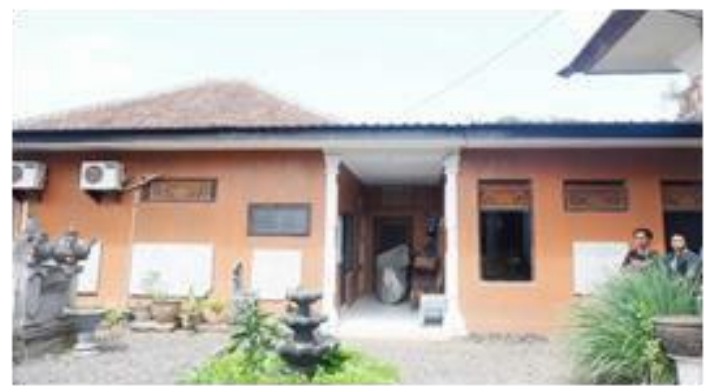

Fig. 6 Main Mandala is very simple

3) Marginality and Centrality

Marginality and Centrality, This can be clearly seen in the design of this building, namely at Nista Mandala. To enter the Karangasem Puri Agung, we enter through the entrance of Bangian Nista Mandala in the form of a brief temple, then we are in the outer space of the Madala Mandala which is where the writer termed "margin space". If we continue to enter again, we will be at the Main Mandala, which is where we enter through the entrance in the form of the Kori Agung. Main author of this Mandala referred to as "central space".

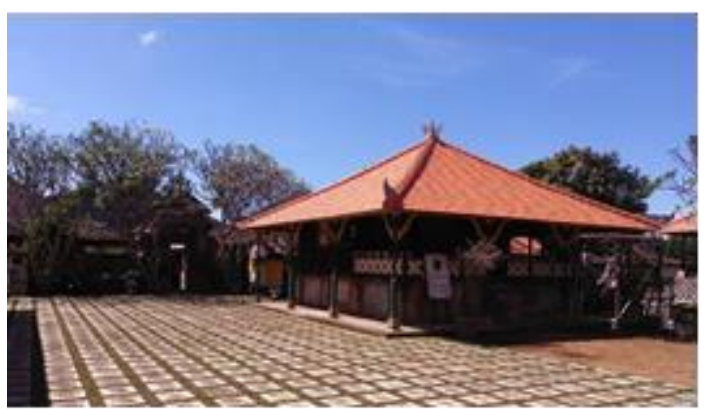

Fig. 7 Kori Agung at Madya Mandala

The solution to the marginality space of the Dutch architect Van der Heutz who collaborated with the local undagi was amazing. Another uniqueness of this Mandala Nista is that there is a great kori Agung Puri Agung Karangasem on the perimeter wall in the west, which forms the roof of the great kori agung. At Madya Mandala, a Gili Building or better known as Bale Kambang was built. On the west side of the bale kambang there is a bridge connecting it to the second courtyard.

The Old Gedong building is also another unique building that can be found on this page, which in the front towards the pool is made open which functioned as a place to watch the shows that were staged at Bale Kambang. Completion of the outer space as "margin space" in this design equals attention to the completion of the inner space.

While the completion of the Main Mandala as a Central space, resolved as in general is not excessive from the outside space or its margin space. Means that in this architectural work rewards the same Marginality and Centrality, in accordance with the strategy or method of architectural design Deconstruction. 
4) Iterability and Meaning

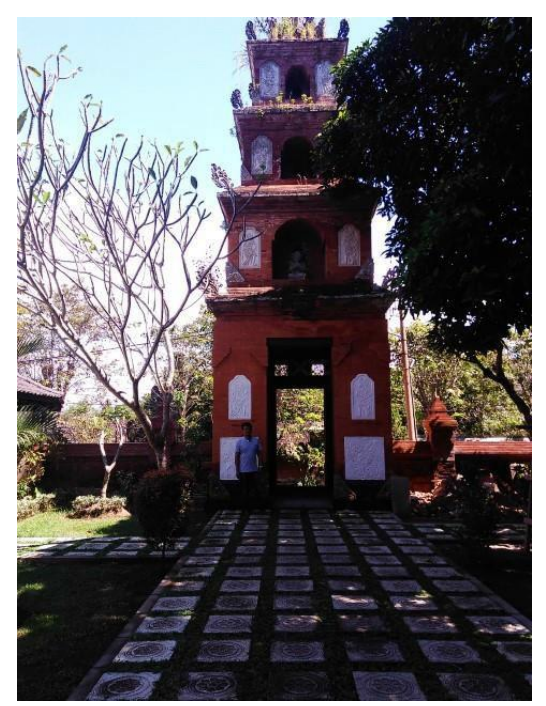

Fig. 8 Candi Kurung at Nista Mandala

For the issue of repetition and meaning in this building, it will be seen from repetition in making the entrance of each mandala, from the entrance to the Nista Mandala section in the form of the Candi Kurung which forms a pagoda. then the next entrance to the Madala Mandala section is also in the form of the Candi Kurung. Then from the Madya Mandala section towards the Main Mandala there is a Kori Agung-shaped door. Although its function is as an entrance, but its shape is different and the ornamental and ornamental arrangements are also different because they have different meanings.

In ornamental ornamentation there are also forms of repetition, but the styles are different and have different meanings. Judging from the repetition of the entrance and ornament form, the Puri Agung Karangasem especially regarding Itterability and Meaning can fulfill the strategy or method of designing with Deconstruction architecture.

If a building is a repetition of the surrounding architectural form, then the building reflects the building's surroundings. Therefore the building also contains and describes the neighbor. When a building is completely different from its context, the building disqualifies itself from the critical action before the building is realized, the same applies to repetitions in the building within the context of its own deconstruction. To understand this better, it must be seen the interdependence of repetition and meaning / meaning or in terms of Derrida Iterability and Meaning (repeated habits and meanings).

\section{CONCLUSIONS}

As a literary and philosophical theory, Deconstruction has been able to provide new discourses in architecture, both as concepts, strategies and methods in 'reading/understanding and designing' architecture. Departing from the concept of text as a network of signs that are traces of other signs, Derrida deconstructs the writings/texts by reading them carefully, so as to find the basis of incoherence. Derrida uses the concept of "Differance" which refers to unlimited possibilities to play with different meanings, so that the definitive interpretation of a text never ends and has a final meaning. From the discussion or reading of Karangasem Puri Agung above, from the perspective of Deconstruction architecture, the following conclusions can be made:

1) The Difference Element, can be expressed through space/space or delay and through two differences regarding prensency and absence (there is and does not exist).

2) Hierarchy Reversal, this is still unclear, but it is lifted from the hierarchy of inner and outer space.

3) Marginality and Centrality, this can be clearly expressed in the equalization of the space outside and inside,

4) Itterability and Meaning, this can be displayed through repetition of the entrance and ornament forms that have a certain meaning.

Deconstruction as a 'Strategy and Method' is believed by the author to be a scalpel that is reliable enough to vulgarly display the wealth of manicures in the form of spatial understanding, values and meanings contained in a traditional Balinese dwelling. From the results of the deconstruction, it was found that the traditional spatial dwelling which in this case was a castle, was actually the result of the deconstruction of the Undagi and assisted by Sangging from a 'House' building, using the principle of being equivalent to 'programmatic deconstruction', to obtain new strengths and definitions.

\section{REFERENCES}

[1] Ardika, I. W., 2004. Bali Tourism: Building TourismCulture and Controling Tourism Culture. In "Bali Towards Jagadhita: Various Perspectives. Denpasar: Bali Post.

[2] Megawangi, I. G. A. Y., 2013. Puri Agung Karangasem: Historical Perspective, Structure and Function and its Potential as a Learning Source. Singaraja: University of Education, Ganesha.

[3] Andiani, 2014. Development Model of Agung Karangasem Castle As a Cultural Attraction of Bali. Singaraja: University of Education, Ganesha.

[4] Papadakis, A C., 1994 Architectural Design: Deconstruction in Architecture, Academy Group LTD, New Edition, London.

[5] Benedikt, M., 1991 " Deconstructing The Kimbell, An Essay on Meaning and Architektur”, Lumen. Inc, New York.

[6] Groat, L. N., 2013. Architectural Research Methods. Hoboken, New Jersey: John Wiley \& Sons, Inc.

[7] Moleong, 2010. Qualitative Research Methodology. Bandung .: PT. Rosdakaarya's teenager.

[8] Agung, A. A. P., 1986. Transition of the Bureaucratic System of the Karangasem Kingdom 1890-1983. Ygyakarta: Gajah Mada University.

[9] Salain, P. R., 2015. Puri Agung Karangasem: The Great Work of East Bali Architecture. In: Opening the Scientific Way. Denpasar: Laras Library, pp. 1-14.

[10] Gelebet, I. N., 1985. Traditional Regional Architecture of Bali. Jakarta: Ministry of Education and Culture.

[11] Dwijendra, N. K. A., 2008. Balinese Traditional House Architecture. Denpasar: Udayana University Press and CV. Bali Media Adhikarsa. 
International Journal of Engineering and Emerging Technology Vol. 4 No. 2 July - December 2019

[12] Arini, A. A. A. K., 2009. Puri Karangasem Establishing Relationships with Islamic Communities and as Art Administrators. Denpasar: Denpasar Art Institute.

[13] Sulistyawati, 2008. Integration of Chinese Architecture into the Architecture of Puri Agung Karangasem. Denpasar: Udayana University Cultural Studies Postgraduate Program.

[14] Kurniawan, A., 2016. The Concept of Tourism Development for Historic Buildings in Karangasem. Denpasar, Warmadewa University.

[15] Wiweka, K., 2014. Analysis of the Tri Hita Karana Concept on the Attraction of Cultural Heritage: A Case Study of Puri Agung Karangasem, Bali. Master of Tourism Journal (JUMPA), 01 (Volume 01, Number 01, July 2014).

[16] Durmus, S. \& Gur, S. O., 2011. Methodology of Deconstruction in Architectural Education. Procedia Social and Behavioral Sciences, Volume 15, pp. 15861594. 